\title{
Catalytic synthesis of $(E)-\alpha, \beta$-unsaturated esters from aldehydes and 1,1-diethoxyethylene
}

\author{
Rubén Manzano ${ }^{1}$, Lidia Ozores ${ }^{1}$, Andreas Job $^{2}$, Lars Rodefeld ${ }^{3}$ \\ and Benjamin List ${ }^{*}, 1$
}

\author{
Preliminary Communication

\section{Address:} \\ ${ }^{1}$ Max-Planck-Institut für Kohlenforschung, Kaiser-Wilhelm-Platz 1, \\ 45470 Mülheim an der Ruhr, Germany, ${ }^{2}$ Saltigo $\mathrm{GmbH}, 51369$ \\ Leverkusen, Germany and ${ }^{3}$ Bayer CropScience AG, 40789 Monheim, \\ Germany \\ Email: \\ Benjamin List* - list@mpi-muelheim.mpg.de \\ * Corresponding author \\ Keywords: \\ 1,1-diethoxyethylene; $\alpha, \beta$-unsaturated esters
}

\section{Open Access}

Beilstein Journal of Organic Chemistry 2009, 5, No. 3. doi:10.3762/bjoc.5.3

Received: 19 December 2008

Accepted: 26 January 2009

Published: 30 January 2009

Editor-in-Chief: J. Clayden

(C) 2009 Manzano et al; licensee Beilstein-Institut. License and terms: see end of document.

\footnotetext{
Abstract

A practical and high yielding synthesis of $\alpha, \beta$-unsaturated esters from aldehydes and 1,1-diethoxyethylene was developed.
}

\section{Introduction}

A number of reactions transforming aldehydes into $\alpha, \beta$-unsaturated esters have been developed and especially Wittig reaction variants are widely used [1]. A general problem with these approaches, however, is their unsatisfactory atom economy resulting in significant by-product formation (Scheme 1, eq $1-2)$. Alternatives have been suggested but a solution that is both as general and efficient as the Wittig procedures and satisfactory with respect to the demand for atom economy is still needed [2-22]. We have recently developed a new approach based on the Knoevenagel condensation of readily available and inexpensive malonate half esters with aldehydes which leads to the formation of water and $\mathrm{CO}_{2}$ as the only by-products (Scheme 1, eq 3) $[23,24]$. Here we describe as a new approach, the boronic acid-catalyzed condensation of ketene dialkyl acetal with aldehydes to furnish $\alpha, \beta$-unsaturated esters in good yields and reliably high (E)-stereoselectivities (Scheme 1, eq 4). Although previously attempted under thermal conditions with poor success, our catalytic reaction is entirely new [25].

We reasoned that the reaction of readily available and inexpensive ketene diethyl acetal [26] or ketene dimethyl acetal (available from Aldrich) with aldehydes upon treatment with a suitable reagent or catalyst could readily lead to the corresponding unsaturated ester and ethanol or methanol as the only by-product. The use of ketene dialkyl acetals for organic transformations is infrequent [27]. To the best of our knowledge, they have been employed in [2+2] cycloadditions [28-30], Diels-Alder processes [31] and reactions with alcohols [32] and $N$-formyl imines [33], to afford orthoesters and $N$-formyl- $\beta$ aminoesters respectively. 


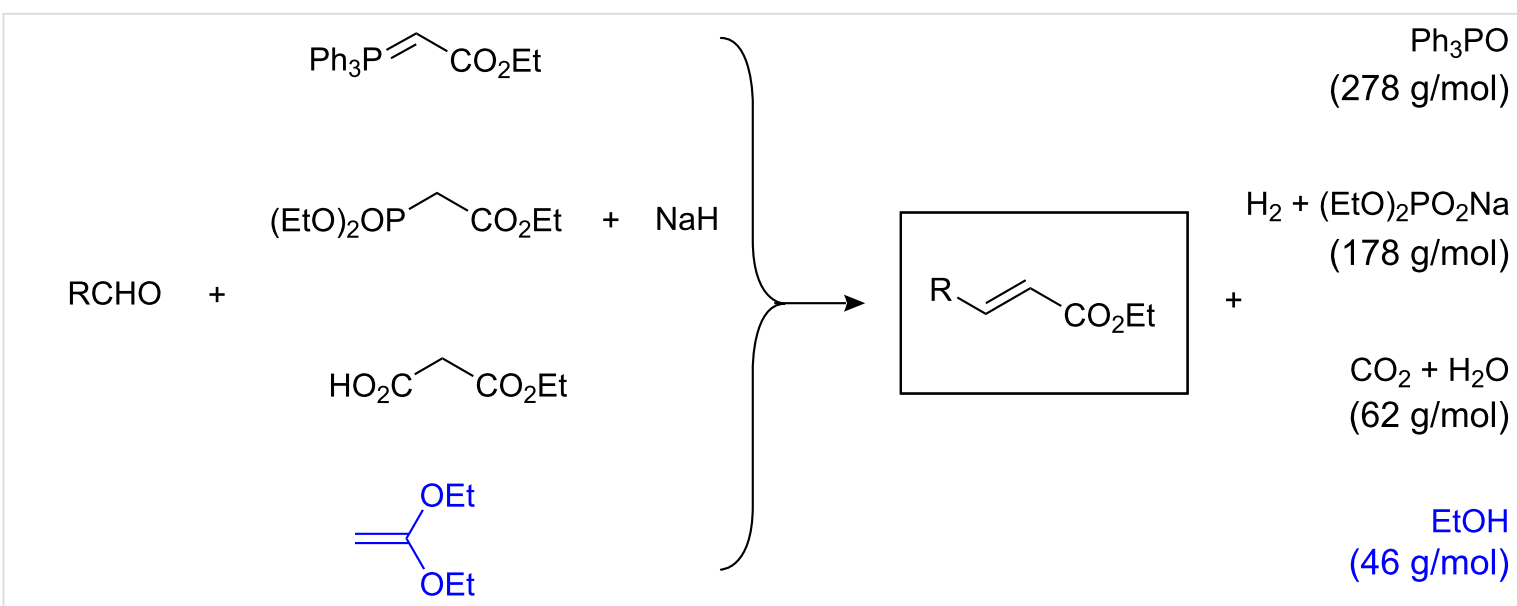

Scheme 1: Conversions of aldehydes into $\alpha, \beta$-unsaturated esters.

\section{Results and Discussion}

Initial experiments revealed that Brønsted acids such as acetic acid indeed catalyze the newly designed transformation. After screening various catalysts and different reaction conditions, we found that boronic acids [34], especially 2,4,5-trifluorophenylboronic acid, proved to be quite active catalysts of the condensation of benzaldehyde with ketene diethyl acetal (Table 1). Brønsted acids are also effective but this particular boronic acid, which possesses both Lewis acidity and Brønsted acidity, was the most active catalyst and gave the highest yields of the corresponding $\alpha, \beta$-unsaturated ester. The optimized procedure involved the slow addition of 1,1-diethoxyethylene to benzaldehyde in the presence of a catalytic amount ( $5 \mathrm{~mol} \%$ ) of $2,4,5$ trifluorophenylboronic acid at $50{ }^{\circ} \mathrm{C}$ in MTBE, affording the corresponding $\alpha, \beta$-unsaturated ester in $98 \%$ yield as the pure (E)-isomer.

The procedure proved general and both aromatic as well as aliphatic aldehydes can be utilized (Table 2). For aromatic aldehydes the yields are typically very high (93-98\%, entries 1-5).

Table 1: Selected results for catalyst screening.

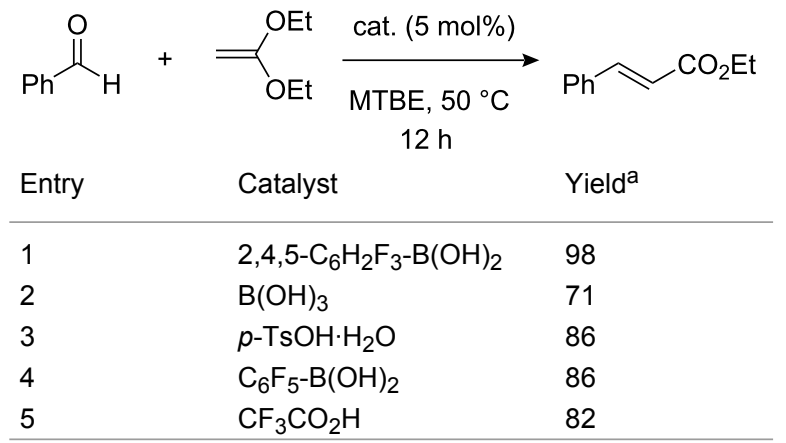

aYield of isolated product
Cinnamaldehyde, as an example of an unsaturated aldehyde gave the desired product in $83 \%$ yield (entry 6 ). The unsaturated esters derived from branched aliphatic aldehydes were isolated in $80-89 \%$ yield (entries 7-8). Even $\alpha$-unbranched, linear aldehydes furnished the expected product (entries 9-10). However, in these cases, the yields are slightly lower (61-64\%). In addition, 1,1-dimethoxyethylene has also been tested and was found to give the corresponding methyl esters analogously.

Despite the absence of any supporting evidence, we envision a plausible mechanism that explains the peculiar effectiveness of boronic acids as catalysts (Scheme 2). Accordingly, the boronic acid functions as a Lewis acid activating the aldehyde but also

Table 2: Olefination of different aldehydes.

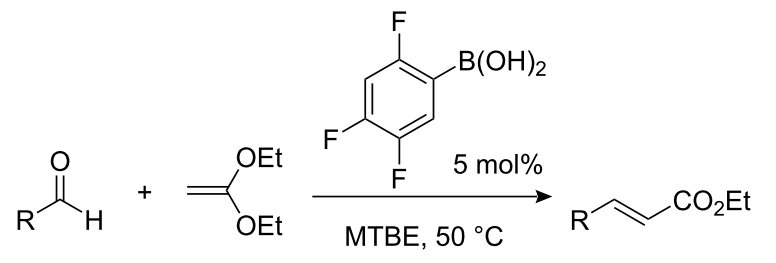
$12 \mathrm{~h}$

\begin{tabular}{lll} 
Entry & $\mathrm{R}$ & Yield $^{\mathrm{a}}$ \\
\hline 1 & $p-\mathrm{MeO}-\mathrm{Ph}$ & 94 \\
2 & $\mathrm{Ph}$ & 98 \\
3 & $p-\mathrm{Br}-\mathrm{Ph}$ & 97 \\
4 & $1-$ naphthyl & 93 \\
5 & $p-\mathrm{MePh}$ & 97 \\
6 & $\mathrm{PhCH}=\mathrm{CH}$ & 83 \\
7 & $\mathrm{Cy}$ & 89 \\
8 & $\mathrm{iPr}$ & 80 \\
9 & $n-\mathrm{C}_{4} \mathrm{H}_{9}$ & 64 \\
10 & $n-\mathrm{C}_{6} \mathrm{H}_{13}$ & 61 \\
\hline
\end{tabular}

aYield of isolated product 


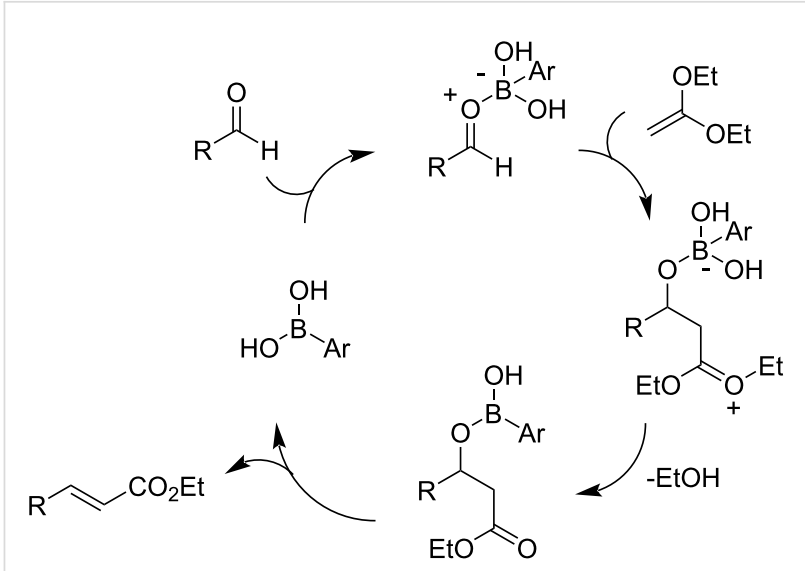

Scheme 2: A plausible mechanism.

as a hydroxide donor facilitating the departure of ethanol from an activated intermediate. Clearly, alternative mechanisms may be proposed.

\section{Experimental}

A solution of benzaldehyde (500 $\mathrm{mg}, 4.7 \mathrm{mmol})$ and 2,4,5trifluorophenylboronic acid ( 0.05 equiv) in MTBE $(2.5 \mathrm{~mL})$ was prepared. After heating the reaction mixture to $50{ }^{\circ} \mathrm{C}$, a solution of ketene diethyl acetal (4 equiv) in MTBE $(2.5 \mathrm{~mL})$ was added dropwise over $2 \mathrm{~h}$, and the reaction was stirred at the same temperature for $12 \mathrm{~h}$. The solvent was removed under vacuum, and the crude material was purified by flash chromatography to afford the pure product (silica gel, hexane/EtOAc 95/ $5)$.

\section{Acknowledgments}

Generous support from the Max-Planck-Society, and the Fonds der Chemischen Industrie is gratefully acknowledged. R.M. thanks the Ministerio de Ciencia e Innovación for a predoctoral fellowship (FPU).

\section{References}

1. Maryanoff, B. E.; Reitz, A. B. Chem. Rev. 1989, 89, 863-927. doi:10.1021/cr00094a007

2. Hatsuda, M.; Kuroda, T.; Seki, M. Synth. Commun. 2003, 33, 427-434. doi:10.1081/SCC-120015773

3. Kisanga, P.; D'Sa, B.; Verkade, J. Tetrahedron 2001, 57, 8047-8052. doi:10.1016/S0040-4020(01)00782-7

4. Herrmann, W. A.; Wang, M. Angew. Chem. 1991, 103, 1709-1711. doi:10.1002/ange.19911031235

5. Ledford, B. E.; Carreira, E. M. Tetrahedron Lett. 1997, 38, 8125-8128. doi:10.1016/S0040-4039(97)10182-4

6. Lee, M.-Y.; Chen, Y.; Zhang, X. P. Organometallics 2003, 22, 4905-4909. doi:10.1021/om034115y
7. Barma, D. K.; Kundu, A.; Bandyopadhyay, A.; Kundu, A.; Sangras, B.; Briot, A.; Mioskowski, C.; Falck, J. R.

Tetrahedron Lett. 2004, 45, 5917-5920. doi:10.1016/j.tetlet.2004.05.113

8. Taguchi, H.; Shimoji, K.; Yamamoto, H.; Nozaki, H. Bull. Chem. Soc. Jpn. 1974, 47, 2529-2531. doi:10.1246/bcsj.47.2529

9. Matui, S.; Tanaka, K.; Kaji, A. Synthesis 1983, 127-128. doi:10.1055/s-1983-30249

10. Huang, Y.; Shen, Y.; Chen, C. Tetrahedron Lett. 1986, 27, 2903-2904. doi:10.1016/S0040-4039(00)84675-4

11. Huang, X.; Xie, L.; Wu, H. Tetrahedron Lett. 1987, 28, 801-802. doi:10.1016/S0040-4039(01)80993-X

12. Huang, Z.-Z.; Ye, S.; Xia, W.; Tang, Y. Chem. Commun. 2001, 1384-1385. doi:10.1039/b104100m

13. Olah, G. A.; Wu, A.-h.; Farooq, O.; Prakash, G. K. S. Synthesis 1988, 537-538. doi:10.1055/s-1988-27628

14. Sampath Kumar, H. M.; Shesha Rao, M.; Joyasawal, S.; Yadav, J. S. Tetrahedron Lett. 2003, 44, 4287-4289. doi:10.1016/S0040-4039(03)00815-3

15. Kagabu, S.; Shimizu, C.; Takahashi, J.; Hara, K.; Koketsu, M.; Ishida, M. Bull. Soc. Chim. Fr. 1992, 129, 435-439.

16. Blakemore, P. R.; Ho, D. K. H.; Nap, W. M. Org. Biomol. Chem. 2005, 3, 1365-1368. doi:10.1039/b500713e

17. Engel, D. A.; Lopez, S. S.; Dudley, G. B. Tetrahedron 2008, 64, 6988-6996. doi:10.1016/j.tet.2008.02.030

18. Concellón, J. M.; Rodríguez-Solla, H.; Díaz, P.; Llavona, R. J. Org. Chem. 2007, 72, 4396-4400. doi:10.1021/jo070209w

19. Smith, J. M.; Greaney, M. F. Tetrahedron Lett. 2007, 48, 8687-8690. doi:10.1016/j.tetlet.2007.10.029

20. Beletskaya, I. P.; Cheprakov, A. V. Chem. Rev. 2000, 100, 3009-3066. doi:10.1021/cr9903048

21. Chatterjee, A. K.; Toste, F. D.; Choi, T.-L.; Grubbs, R. H. Adv. Synth. Catal. 2002, 344, 634-637. doi:10.1002/1615-4169(200208)344:6/7<634::AID-ADSC634>3.0.CO;2 $-\mathrm{K}$

22. Zeitler, K. Org. Lett. 2006, 8, 637-640. doi:10.1021/ol052826h

23. List, B.; Doehring, A.; Hechavarria Fonseca, M. T.; Wobser, K.; van Thienen, H.; Rios Torres, R.; Llamas Galilea, P. Adv. Synth. Catal. 2005, 347, 1558-1560. doi:10.1002/adsc.200505196

24. List, B.; Doehring, A.; Hechavarria Fonseca, M. T.; Job, A.; Rios Torres, R. Tetrahedron 2006, 62, 476-482. doi:10.1016/j.tet.2005.09.081

25. McElvain, S. M.; Degginger, E. R.; Behun, J. D. J. Am. Chem. Soc. 1954, 76, 5736-5739. doi:10.1021/ja01651a034

26. McElvain, S. M.; Kundiger, D. Ketene Diethylacetal. In Organic Syntheses, Collective Volume 3; Horning, E. C., Ed.; John Wiley \& Sons: New York, 1955; pp 506-508.

27. McElvain, S. M. Chem. Rev. 1949, 45, 453-492. doi:10.1021/cr60142a003

28. Avenoza, A.; Busto, J. H.; Canal, N.; Peregrina, J. M. Chem. Commun. 2003, 1376-1377. doi:10.1039/b302000b

29. Avenoza, A.; Busto, J. H.; Canal, N.; Peregrina, J. M. J. Org. Chem. 2005, 70, 330-333. doi:10.1021/jo048943s

30. Rustullet, A.; Alibés, R.; de March, P.; Figueredo, M.; Font, J. Org. Lett. 2007, 9, 2827-2830. doi:10.1021/ol0710616

31. Balázs, L.; Kádas, I.; Tõke, L. Tetrahedron Lett. 2000, 41, 7583-7587. doi:10.1016/S0040-4039(00)01302-2

32. Cosgrove, K. L.; McGeary, R. P. Synlett 2008, 2425-2428. doi:10.1055/s-2008-1078215 
33. Rossen, K.; Jakubec, P.; Kiesel, M.; Janik, M.

Tetrahedron Lett. 2005, 46, 1819-1821.

doi:10.1016/j.tetlet.2005.01.114

34. Ishihara, K.; Ohara, S.; Yamamoto, $\mathrm{H}$.

J. Org. Chem. 1996, 61, 4196-4197. doi:10.1021/jo9606564

\section{License and Terms}

This is an Open Access article under the terms of the Creative Commons Attribution License

(http://creativecommons.org/licenses/by/2.0), which permits unrestricted use, distribution, and reproduction in any medium, provided the original work is properly cited.

The license is subject to the Beilstein Journal of Organic Chemistry terms and conditions:

(http://www.beilstein-journals.org/bjoc)

The definitive version of this article is the electronic one which can be found at: doi:10.3762/bjoc. 5.3 